\title{
Neuro-ophthalmological complications of enlargement of the third ventricle
}

\author{
ROBERT H. OSHER, JAMES J. CORBETT, NORMAN J. SCHATZ, \\ PETER J. SAVINO, AND LINDA S. ORR \\ From the Neuro-ophthalmology Unit of the Wills Eye Hospital, and the Departments of Ophthalmology \\ and Neurology, Jefferson Medical College, Philadelphia
}

SUMMARY A wide variety of visual sensory and ocular motor problems may occur as a direct result of enlargement of the third ventricle. Four patients are described with optic nerve dysfunction, partial third nerve palsy, proptosis, and Sylvian aqueduct syndrome all resulting from an enlarged third ventricle. The pathogenetic mechanisms are discussed.

The close relationship of the third ventricle to the optic chiasma, optic nerves, and cavernous sinus provides the anatomical substrate for a variety of neuro-ophthalmological disorders that can result when there is ventricular enlargement. Posterior fossa lesions may produce a false localising chiasmal syndrome with bitemporal hemianopia and bilateral optic atrophy, secondary to an enlarged third ventricle acting as a suprasellar mass (Weber, 1906; Oppenheim, 1911; Wilbrand and Saenger, 1913; Learmonth, 1931; Sinclair and Dott, 1931; Wohlwill, 1931; Wagener and Cusick, 1937; Weinberger and Webster, 1941; Walsh and Hoyt, 1969). Unilateral optic nerve dysfunction, infranuclear motility disturbances, unilateral proptosis, and the Sylvian aqueduct syndrome produced by internal hydrocephalus are rare (Lassman et al., 1960; Lerner et al., 1969; Swash, 1974; Shapiro et al., 1976). Four patients are described who demonstrate these unusual clinical neuro-ophthalmological problems of dilatation of the third ventricle.

\section{Case reports}

CASE 1

A 38-year-old woman complained of progressive blurring of vision in her left eye for 3 months. A normal eye examination had been recorded 8 months earlier. On neuro-ophthalmological examination visual acuity was $6 / 5$ OD and 6/60 OS. Ocular motility was normal. The pupils were equal, with a left afferent defect (Marcus Gunn pupil). Visual

Address for reprints: Dr Norman J. Schatz, Neuroophthalmology Unit, Wills Eye Hospital, 1601 Spring Garden Street, Philadelphia, Pa. 19130, USA fields were full in the right eye, and the left visual field was markedly constricted, with only a small paracentral island of vision remaining (Fig. 1). The right optic disc was normal but the left optic disc was pale. The neurological examination was otherwise normal.

Skull radiographs showed that the left optic canal was $2 \mathrm{~mm}$ larger than the right. Computerised axial tomography showed dilatation of the third and lateral ventricles with no evidence of a mass lesion (Fig. 2). Pancerebral arteriography demonstrated a small arteriovenous (A-V) malformation in the left occipital region supplied by a branch of the left anterior cerebral artery, middle cerebral artery, and posterior cerebral artery. The fourth ventricle was of normal size on pneumoencephalography, but air did not pass beyond the rostral end of the Sylvian aqueduct. Ventriculography was not performed.

A ventriculoperitoneal shunt was placed, and over the next week visual acuity improved from $6 / 60$ to $6 / 15 \mathrm{OS}$, where it has remained to the present.

Comment. A 38-year-old woman with visual blurring in 1 eye was found to have monocular visual loss, an afferent pupillary defect, a constricted visual field, and a pale disc. This was thought to be secondary to left optic nerve compression by an enlarged third ventricle resulting from aqueductal stenosis.

CASE 2

A 9-year-old boy was found by a school nurse to have poor vision in his right eye 2 years before our initial examination. Neuro-ophthalmological examination revealed hand motion vision OD and 6/6 OS. There was left blepharoptosis, and the eye could not be elevated in abduction. Pupils were equal, with a 
Fig. 1 Case 1. Severely constricted left visual field consistent with an optic nerve defect. Visual field in the right eye is normal

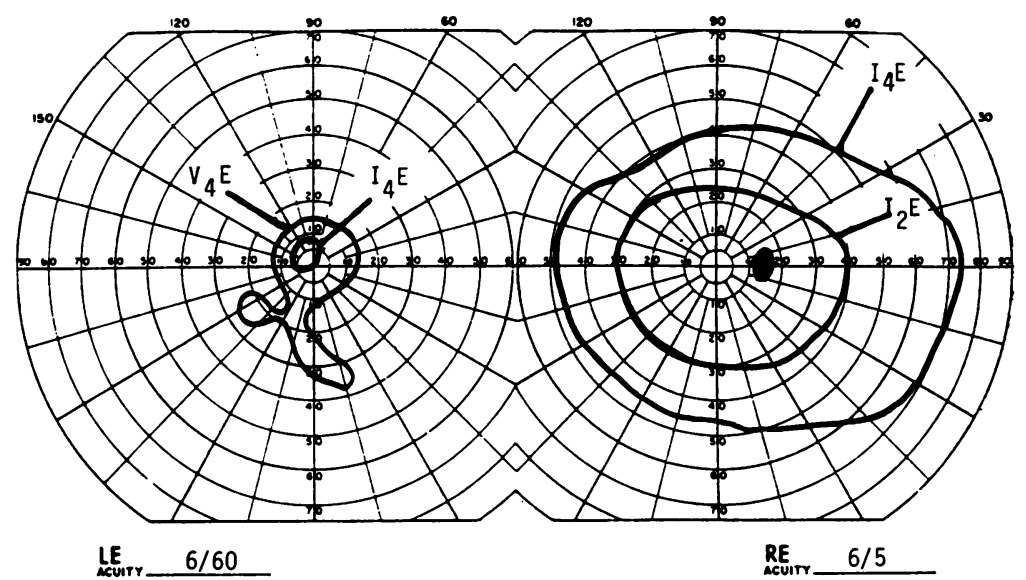

concentration and memory, and had become withdrawn.

Head circumference was $60 \mathrm{~cm}$. Examination of his mental status confirmed impaired memory, dis-

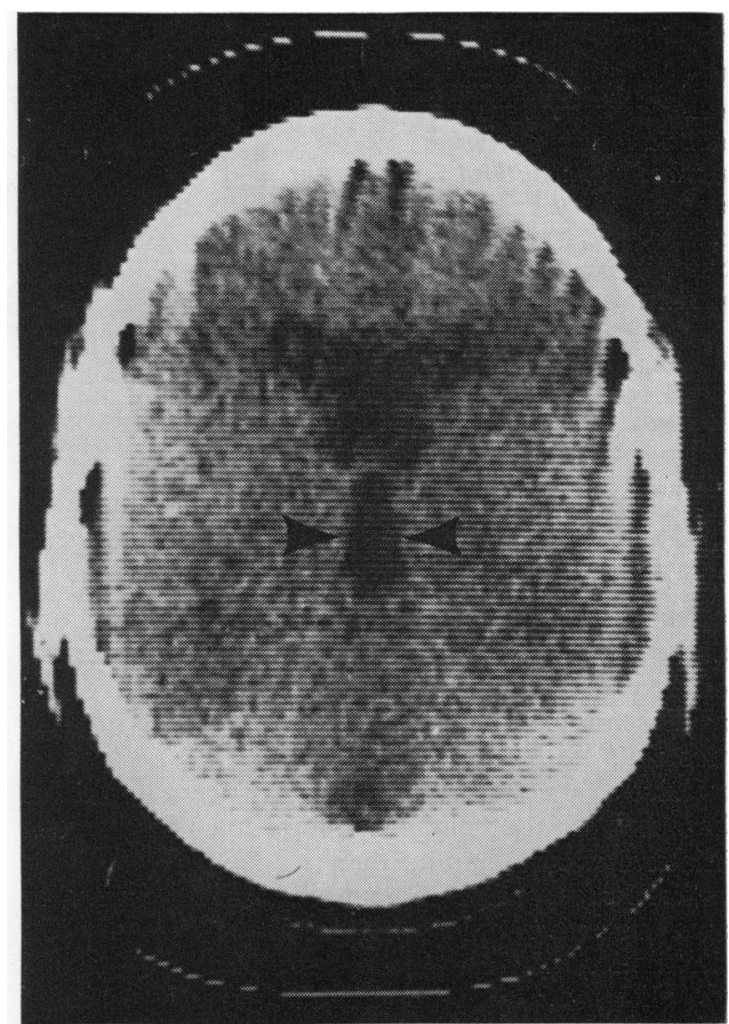

Fig. 2 Case 1. Computerised axial tomography scan shows dilated third (arrows) and lateral ventricles with decreased density at the angles of the frontal horns within the cerebral white matter consistent with increased periventricular water 


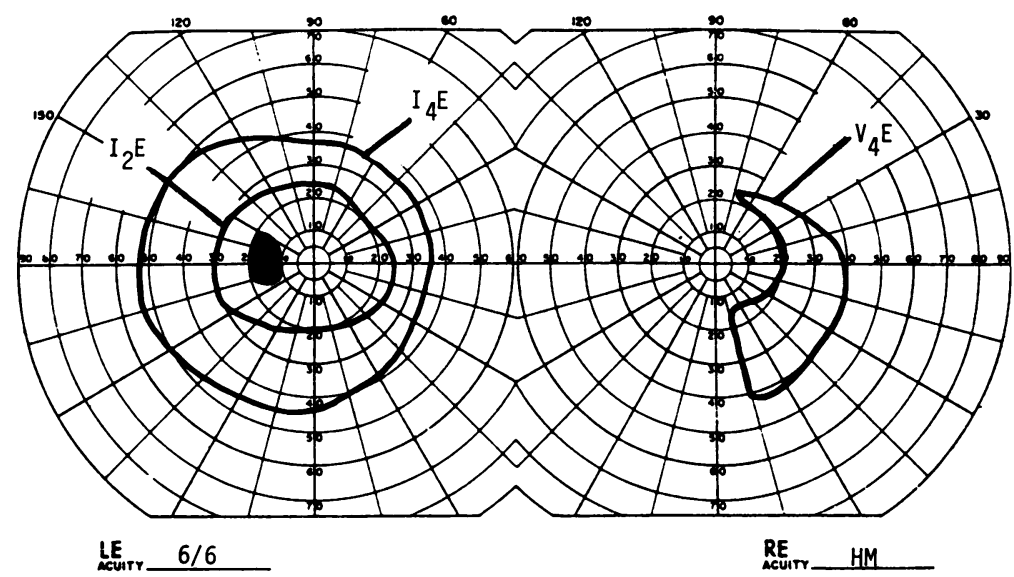

Fig. 3 Case 2. Visual field in right eye shows a residual temporal island of hand movement vision. The blind spot in the left eye was enlarged

Fig. 4 Case 2. Combined pneumoencephalogram and ventriculogram showing $a$ markedly dilated third ventricle extending to the planum sphenoidale. (Arrows define the anterior extent of the third ventricle)

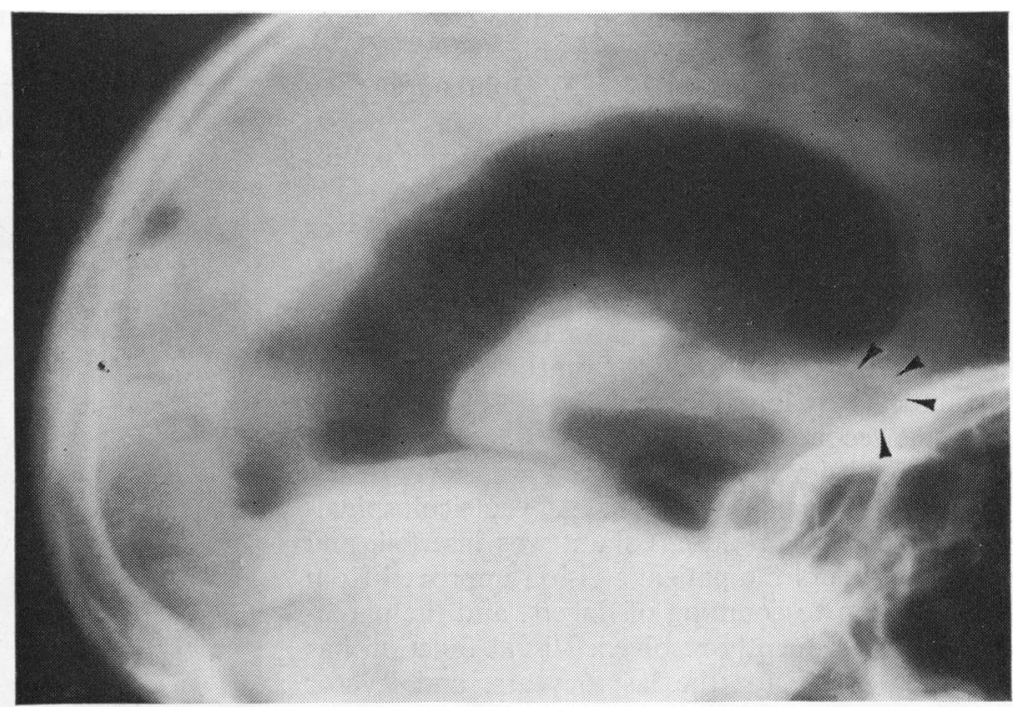

orientation to time and place, and poor abstracting and calculating abilities. There was $5 \mathrm{~mm}$ proptosis of the right eye, with conjunctival congestion. Visual acuity was $6 / 15$ OD and $6 / 18$ OS. Ocular motility was full. Both pupils reacted sluggishly without a relative afferent defect. Visual fields were unreliable because of the patient's dementia. There was bilateral chronic papilloedema.

Skull $x$-rays and tomography of the parasellar area revealed separation of sutures, complete destruction of the sella turcica and upper third of the clivus, with obliteration of the sphenoid sinus (Fig. 5). The sphenoid wings and planum sphenoidale were demineralised, a finding consistent with longstanding increased intracranial pressure. The superior orbital fissures were widened and the internal auditory canals were enlarged (Fig. 6). Ventriculo- graphy showed dilatation of the lateral and third ventricles. The remnants of the sella turcica were occupied by a massively dilated third ventricle. Review of skull $x$-rays taken at the time of a fall 7 years earlier revealed an enlarged sella turcica and separation of sutures which were unrecognised at that time.

Ventriculoperitoneal shunting was performed and visual acuity returned to $6 / 6 \mathrm{OD}$ and $6 / 9 \mathrm{OS}$, with reduction of proptosis of the right eye. He has been followed up for 3 years, with no further problems.

Comment. A 19-year-old man with deterioration of mental function, personality change, visual loss, proptosis, and papilloedema was found to have a dilated third ventricle secondary to aqueductal stenosis. The third ventricle extended into the parasellar area and it is postulated that proptosis 
Fig. 5 Case 3. Obliteration of the bony landmarks of the sella turcica and upper third of the clivus due to third ventricle compression. There is a marked thinning of the squamous portions of the temporal and parietal bones

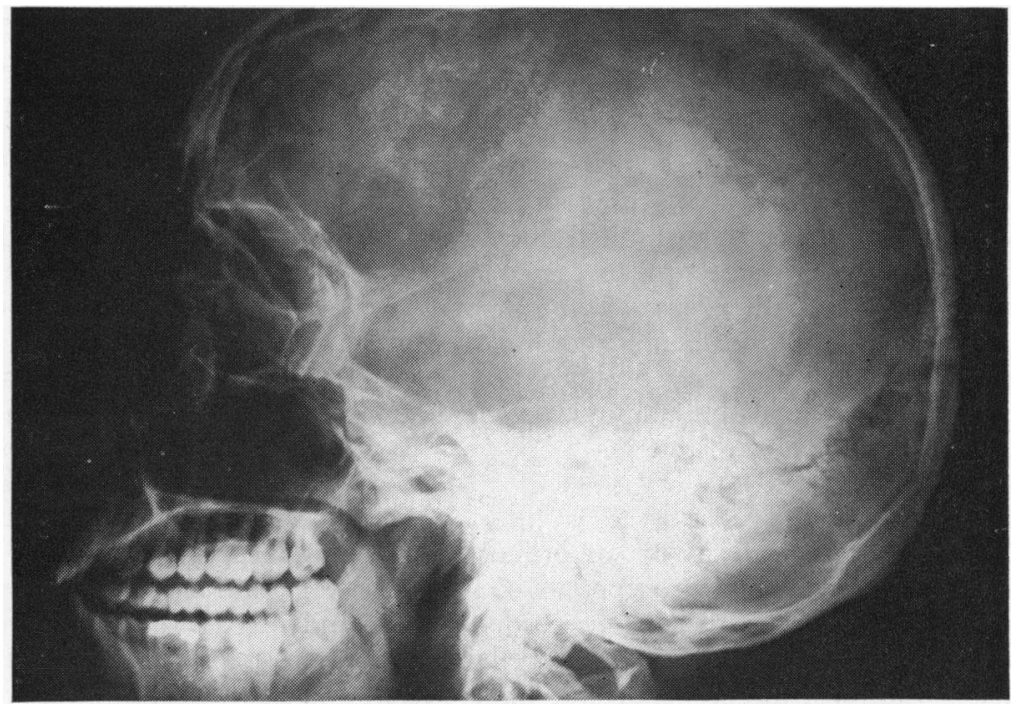

resulted from obstruction of venous return by compression of the cavernous sinus.

\section{CASE 4}

An 18-year-old girl presented with frontal headache and transient episodes of visual blurring. The headaches were increased in severity with the Valsalva manoeuvre. Three months before she was admitted to hospital a swishing sound developed in her head.

Visual acuity was $6 / 6 \mathrm{OU}$ and bilateral papilloedema was present. She had an incongruous left inferior quandrantanopsia. Pupils were $4 \mathrm{~mm}$ OD and $5 \mathrm{~mm}$ OS; both pupils reacted sluggishly to light but were briskly reactive to convergence. Ocular motility was normal. A bruit could be heard over the entire head. Pancerebral angiography, computerised axial tomography scan, and pneumoencephalography were consistent with a diagnosis of stenosis of the Sylvian aqueduct. One month after placement of a Torkildsen tube the patient reappeared complaining of bifrontal headache, recurrence of the 'swishing' sound, and transient visual obscurations. Initial examination revealed only papilloedema and coarse upbeating nystagmus in the primary position. Subsequently over the next week she developed convergence-retraction nystagmus on attempts at saccadic eye movement in all directions, paralysis of upgaze with preserved doll's head manoeuvre, and pathological lid retraction on attempts at up- or downgaze. Her eyes became progressively more convergent and tended to remain in tonic downgaze. The Torkildsen tube was replaced by a ventriculoperitoneal shunt, with prompt disappearance of all findings.
Comment. A young woman with aqueductal stenosis had a Torkildsen tube placed, and shunt dysfunction promptly produced a classic Sylvian aqueduct syndrome associated with massive ventri-

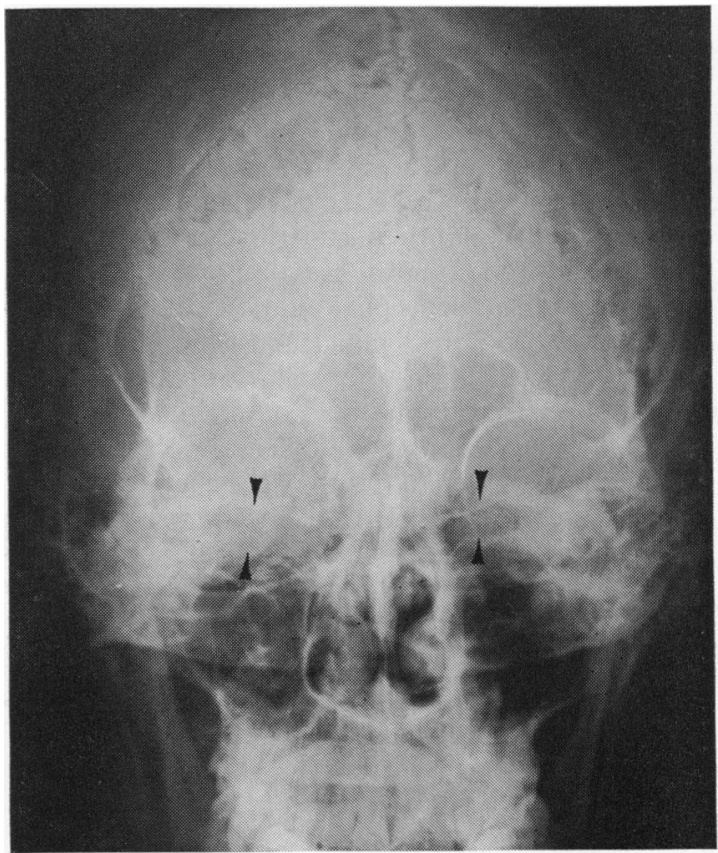

Fig. 6 Case 3. Marked demineralisation of the sphenoid bones and widening of the superior orbital fissures is seen. Enlargement of the internal auditory canals (arrows) is a sign of long-standing increased intracranial pressure. Prominent separation of sutures is unusual in a patient this age (19 years old). The optic canals were not enlarged 
cular dilatation. Relief of pressure resulted in remission of signs and symptoms.

\section{Discussion}

The neuro-ophthalmological complications of an enlarged third ventricle result from the anatomical proximity of this structure to the cavernous sinus, anterior visual pathways, pretectum, and the cranial nerves responsible for ocular motility. Compression of these structures may produce proptosis, optic nerve dysfunction, ophthalmoplegia, or the Sylvian aqueduct syndrome (Table 1).

\section{PROPTOSIS}

Proptosis, ordinarily a sign of orbital disease, has been reported with hydrocephalus. Gardner (1948) reported a patient with unilateral exophthalmos and a large haemangiomatous cerebellar cyst. An ipsilateral post-traumatic orbital plate defect and encephalocele provided the orbital cause for proptosis related to her hydrocephalus. Green and Oliver (1968) described bilateral exophthalmos in a patient with aqueductal stenosis and concomitant thyrotoxicosis. Remarkably, both the eye signs and abnormal thyroid function values remitted after a ventricular-jugular shunt was performed. Shapiro and associates (1976) reported a 46-year-old woman with a history of monocular, post-traumatic blindness and optic atrophy, who developed dementia, proptosis, conjunctival chemosis, and ophthalmoplegia in the blind eye. In the contralateral eye visual acuity was $6 / 30$, with a superior temporal quadrantanopia. The fundus was reportedly normal. Combined pneumoencephalography and ventriculography showed aqueductal stenosis with a dilated third ventricle filling the sella turcica. After a ventriculoperitoneal shunt the conjunctival chemosis, ophthalmoplegia, and field defect resolved. Shunt malfunction resulted in return of the chemosis.

Raised cavernous sinus venous pressure can produce proptosis. This has been produced experimentally (Brunton, 1949) and documented clinically

Table 1

\footnotetext{
A. Anterior visual pathway compression

1. Optic nerve

2. Chiasm

3. Optic tract

B. Motility disturbance

1. Supranuclear-Sylvian aqueduct syndrome

2. Infranuclear-Cranial nerve palsy III, IV, VI (complete and partial)

C. Proptosis

Cavernous sinus compression

Erosion of sphenoid wings by enlarged temporal lobe
}

in patients with a carotid-cavernous fistulas, as well as those with parasellar lesions such as pituitary adenomas (Boschi and Campailla, 1932; Spaeth, 1937; Weinberger et al., 1940; Dixon, 1941; Meadows, 1945; Walsh, 1947 and with aneurysms (Jefferson, 1937; Dixon, 1941). A dilated third ventricle which fills the sella turcica can clearly produce cavernous sinus compression and result in proptosis, as in our third patient.

\section{OPHTHALMOPLEGIA}

The ocular motility patterns described in patients with an enlarged third ventricle have been limited to vertical supranuclear gaze palsies with posterior third ventricular dilatation (see below) and nonspecific abducens nerve palsies which reflect increased intracranial pressure.

The patient described by Shapiro et al. (1976) had marked unilateral limitation of eye movement, which resolved when a shunt was placed. Our second patient had an enlarged third ventricle which produced superior division third nerve paresis, presumably related to cavernous sinus compression as well as direct unilateral optic nerve compression.

\section{SYLVIAN AQUEDUCT SYNDROME}

Downward deviation of the eyes in children with aqueductal stenosis was ascribed by West (1848) to depression of the orbital roof. Later reports suggest that this symptom is actually due to the Sylvian aqueduct syndrome. This clinical constellation of convergence-retraction nystagmus, light-near dissociation of the pupils, pathological lid retraction, and inability to perform saccadic or pursuit upward movements, secondary to an enlarged posterior third ventricle and dilatation of the anterior Sylvian aqueduct, has been described in a number of publications since Pennybacker's observations on 5 persons with aqueductal stenosis (Pennybacker, 1940; Lerner, 1969; Swash, 1974; Chattha and DeLong, 1975). This syndrome is characteristic in patients with aqueductal stenosis who have become shunt-dependent or in whom aqueductal stenosis is relatively acute in onset (Chattha and DeLong, 1975). Shunt failure promptly results in reappearance of the symptoms and signs, which remit when the shunt is again functional (Swash, 1974).

\section{VISUAL PATHWAY INVOLVEMENT}

As early as 1713 Cheselden described an optic nerve which was 'crushed flat' in a patient with hydrocephalus. Bitemporal hemianopia resulting from bulging of the floor of the third ventricle in a patient with hydrocephalus was first reported by Weber (1906), and individual patients have subsequently been reported by Oppenheim (1911), 
Wilbrand and Saenger (1913), Learmonth et al. (1931), Sinclair and Dott (1931), Wohlwill (1931), Wagener and Cusick (1937), Weinberger and Webster (1941), and Walsh and Hoyt (1969). A neoplasm in the posterior fossa (usually cerebellar) was the underlying lesion in most of these patients. Aqueductal stenosis and postmeningitic adhesions were less common causes, Bitemporal hemianopias in patients with internal hydrocephalus are probably produced by downward displacement of a distended third ventricle and compression of the optic chiasma. Ventriculostomy resulting in postoperative visual field improvement has provided additional evidence of the mass effect of the third ventricle (Sinclair and Dott, 1931).

Homonymous hemianopia has also been reported as a result of a dilated third ventricle. Wagener and Cusick (1937) described 1 patient with an incongruous homonymous hemianopia due to a posterior fossa lesion. Four patients each with homonymous hemianopia and a cerebellar tumour were reported by Weinberger and Webster (1941). These visual field defects may be accounted for by either of 2 mechanisms. The first suggests that downward displacement of a distended third ventricle against a prefixed chiasma may result in optic tract compression. An alternative explanation proposes that the distended third ventricle ventrally displaces the optic chiasma and stretches the optic tract over the posterior communicating artery (Fay and Grant, 1923; Weinberger and Webster, 1941; Hughes, 1946).

Binasal hemianopia has been described as a feature of third ventricular distension (Cushing and Walker, 1912). They postulated that the dilated third ventricle ventrally displaced the optic nerve and adjoining chiasma against the resistant, pulsatile carotid arteries, thus producing the binasal field defect. The illnesses reported by Walker and Cushing were heterogeneous, and the only common features were chronic papilloedema and secondary optic atrophy. It is our opinion that binasal defects described by Cushing and Walker were more likely to have been caused by the long-standing papilloedema than by chiasmal compression by a dilatated third ventricle (Dersh and Schlezinger, 1959).

A wide variety of other visual field defects have been reported in association with ventricular dilatation, including bilateral central scotomas (Wagener and Cusick, 1937). Unilateral optic nerve dysfunction was described in 1 patient (Lassmann et al., 1960). A 10-year-old boy with normal visual acuity developed temporal disc pallor in the right eye followed by superior temporal sector visual field defect in the left eye associated with bilateral papilloedema over a 9-month period. Cerebrospinal fluid pressure was raised, and the diagnosis of aqueductal stenosis was made. After a ventricular shunt operation his papilloedema disappeared and the visual field defect partially regressed. The authors concluded that the dilated third ventricle had pushed the chiasma forward and downward, causing 1 optic nerve to impinge against the lateral aspect of the tuberculum sellae.

Patients 1 and 2 had purely unilateral optic nerve dysfunction, shown by a monocular reduction in visual acuity, afferent pupillary defect, visual field deficit, and an atrophic disc. Asymmetrical expansion of an enlarged third ventricle resulting in optic nerve compression is an attractive explanation of this unilateral optic nerve syndrome.

Dilatation of the third ventricle can produce a wide variety of visual symptoms. Compression of optic nerve, chiasma, or optic tract may produce monocular or binocular visual field defects. Disturbances of ocular motility may result either from direct compression of the cavernous sinus and the motor nerves or from distension of the pretectal and periaqueductal regions. More remote effects with monocular proptosis can also be seen as the result of cavernous sinus compression and venous distension.

\section{References}

Brunton, C. E. (1949). Exophthalmos. Physiological Reviews, 29, 260-280.

Boschi, G., and Campailla, G. (1932). Sindrome del seno cavernoso da adenoma ipofisario. Rivista Oto-neurooftalmologica, 9, 414.

Chattha, A. S., and DeLong, G. R. (1975). Sylvian aqueduct syndrome as a sign of acute obstructive hydrocephalus in children. Journal of Neurology, Neurosurgery and Psychiatry, 38, 288-297.

Cheselden, W. (1713). Some anatomical observations. Philadelphia Transactions, 28, 281.

Cushing, H., and Walker, C. B. (1912). Distortions of the visual fields in cases of brain tumor. Binasal hemianopsia. Archives of Ophthalmology, 41, 559-598.

Dersh, J., and Schlezinger, N. S. (1959). Inferior nasal quadrantanopsia in pseudotumor cerebri. Archives of Neurology, 1, 695-699.

Dixon, G. J. (1941). Unilateral exophthalmos. Brain, 64, 73-89.

Fay, T., and Grant, F. C. (1923). Lesions of the optic chiasm and tracts with relation to the adjacent vascular structures. Archives of Neurology and Psychiatry, 9, 739-750.

Gardner, W. J. (1948). Unilateral exophthalmos due to cerebellar tumor and orbital defect. Journal of Neurosurgery, 5, 500-502.

Green, R., and Oliver, L. C. (1968). Remission of thyrotoxicosis and exophthalmos after drainage of aqueduct of Sylvius. British Medical Journal, 4, 412-413.

Hughes, E. B. C. (1946). Some observations on the visual fields in hydrocephalus. Journal of Neurology, Neurosurgery and Psychiatry, 9, 30-39.

Jefferson, G. (1937). Compression of the chiasm, optic nerves and optic tracts by intracranial aneurysms. Brain, 60, 444-497. 
Lassman, L. R., Cullen, J. F., and Howat, J. M. L. (1960). Stenosis of the aqueduct of Sylvius. American Journal of Ophthalmology, 49, 261-266.

Learmonth, J. R., Lillie, W. I., and Kernohan, J. W. (1931) Unusual surgical lesions affecting the optic nerves and chiasm. American Journal of Ophthalmology, 14, 738-749.

Lerner, M. A., et al. (1969). Parinaud's syndrome in aqueduct stenosis: its mechanism and ventriculographic features. British Journal of Radiology, 42, 310-322.

Meadows, S. P. (1945). Orbital tumours. Proceedings of the Royal Society of Medicine, 38, 18-24.

Oppenheim, H. (1911). In Textbook of Nervous Diseases, vol. 2, p. 912 . Schulze: Edinburgh.

Pennybacker, J. (1940). Stenosis of the aqueduct of Sylvius. Proceedings of the Royal Society of Medicine, 33, 507512.

Shapiro, K., Saiontz, H., and Shulman, K. (1976). Unilateral proptosis and visual field defect associated with hydrocephalus. Archives of Neurology, 33, 663-664.

Sinclair, A. A. H., and Dott, N. M. (1931). Hydrocephalus simulating tumour in the production of chiasmal and other parahypophysial lesions. Transactions of the Ophthalmological Society of the United Kingdom, 51, 232-246.

Spaeth, E. B. (1937). Pathogenesis of unilateral exophthalmos. Archives of Ophthalmology, 18, 107-148.

Swash, M. (1974). Periaqueductal dysfunction (the Sylvian aqueduct syndrome): a sign of hydrocephalus? Journal of Neurology, Neurosurgery and Psychiatry, 37, 21-26.

Wagener, H. P., and Cusick, P. L. (1937). Chiasmal syndromes produced by lesions in the posterior fossa. Archives of Ophthalmology, 18, 887-891.

Walsh, F. B. (1947). In Clinical Neuro-Ophthalmology, p. 1171. Williams \& Wilkins: Baltimore.

Walsh, F. B., and Hoyt, W. F. (1969). In Clinical NeuroOphthalmology, 3rd edn., pp. 72, 2211. Williams \& Wilkins: Baltimore.

Weber, L. W. (1906). Zur Symptomatologie und Pathogenese des erworbene Hydrocephalus internus. Archiv für Psychiatrie und Nervenkrankheiten, 41, 64-133.

Weinberger, L. M., Adler, F. H., and Grant, F. C. (1940). Primary pituitary adenoma and the syndrome of the cavernous sinus. Archives of Ophthalmology, 24, 1197-1236.

Weinberger, L. M., and Webster, J. E. (1941). Visual field defects associated with cerebellar tumors. Archives of Ophthalmology, 25, 128-138.

West, C. (1848). Quoted in Russell, D. S. (1949). Observations on the pathology of hydrocephalus. MRC Special Report Series, 265, p. 117. HMSO.

Wilbrand, H., and Saenger, A. (1913). In Die Neurologie des Auges. By J. W. Bergmann. Wiesbaden: München.

Wohlwill, F. (1931). Der Hydrocephalus internus. In Kurzes Handbuch der Ophthalmologie, vol. 6, pp. 36-40. By F. Schick and A. Bruckner. Berlin. 